\title{
Deaths Caused by Epidural Hemorrhage and skull base fracture Due Blunt Force Trauma
}

\author{
Marbun Doaris Ingrid ${ }^{\mathrm{a}}$, Rahmadsyah ${ }^{\mathrm{b}}$, Adrian Rival ${ }^{\mathrm{c}}$, Oktafianna Malau ${ }^{\mathrm{d},}$ Binsar H \\ Lubis $^{\mathrm{e}}$ \\ malauokta@gmail.com
}

Department of Forensic and Medical Sciences RSUP H Adam Malik - Faculty of Medicine, University of North Sumatra Medan - Indonesia

\begin{abstract}
Epidural hematom is one of the most common types of intracranial bleeding due to skull fractures. Epidural hematomas is the accumulation of blood and blood clots between the dura mater layer and the skull bone. Epidural hematomas can occur in anyone and any age. Epidural hematomas occur as a result of head trauma, which is usually associated with skull bone fractures and blood vessel lacerations. A very prominent symptom is that consciousness decreases progressively. Patients with this condition often appear bruised around the eyes and behind the ears. Often also visible fluid that comes out in the nasal passages or ears. Reported a case at the Department of Forensic and Medical Sciences Of Bhayangkara General Hospital TK II Medan City, explained that at a written request from the Padang Lawas Resort Police. The victim was a 14-year-old male student. From the results of external examination found bruises on the head and forehead, On examination in the discovery of blood absorption on the inner scalp, found blood clots on the surface of the thick membrane of the brain, fractures the base of the skull. From the results of external and autopsy concluded the post mortem interval is 24 to 36 hours.and the cause of death is Epidural Hemorrhage due to fractures of the skull due to blunt force trauma on the head
\end{abstract}

Keyword: Epidural hemorrhage, skull base fracture, blunt force trauma

\section{Introduction}

Internationally the frequency of epidural hematoma events is about the same as the incidence rate in the United States. People at risk of developing EDH are elderly people who have walking problems and often fall. $60 \%$ of epidural hematomas are under the age of 20, and rarely occur at less than 2 years of age and over 60 years of age. Mortality rates increased in patients younger than 5 years of age and over 55 years old. More occurs in men than women by a ratio of $4: 1$ 


\section{Etiology}

Epidural hematomas can occur in anyone and any age, some conditions that can cause epidural hematoms are such as a collision on the head in a motorcycle accident. Epidural hematomas occur as a result of head trauma, which is usually associated with skull bone fractures and blood vessel lacerations. ${ }^{4.11}$

Under normal circumstances, there is no epidural space in the cranium. Dura is attached to the cranium. Bleeding usually occurs with a parietal temporal skull fracture where there is a laceration of the arteries or veins of the meningea media. In rare cases, these blood vessels can tear in the absence of a fracture. This condition results in the separation of attachment between dura and cranium and gives rise to an epidural space. Continued bleeding will force the dura to separate further, and cause the hematoma to become the mass that fills the space.

\section{Case Report}

Reported a case at the Department of Forensic and Medical Sciences Bhayangkara TK II General Hospital Medan City, explained that by a written request from the Padang Lawas Resort Police. The victim was a 14-year-old male student.

In the victim found bruises on the neck, back, waist, upper and lower limbs that do not disappear with emphasis, do not find stiff corpses, found the lower right abdomen greenish from the results of external examination found bruises on the head and forehead. Found bluish lips, bluish-colored fingertips, pale toe tips. From the results of the examination in found bleeding spots on the lungs and heart, at the cutting of the lungs found a blackish-red diluted fluid mixed with fine foam that is difficult to break. Found blood absorption on the inner scalp and blood clots on the surface of the thick membrane of the brain, fractures of the base of the skull.

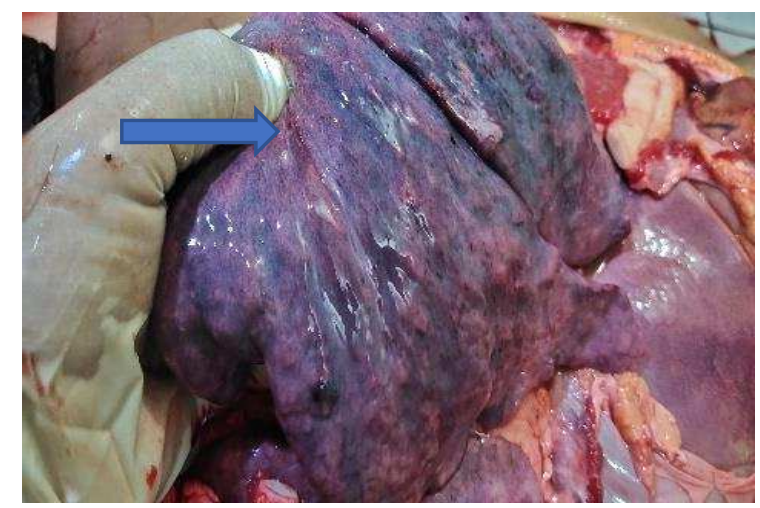

Figure 1. bleeding spots on the lungs

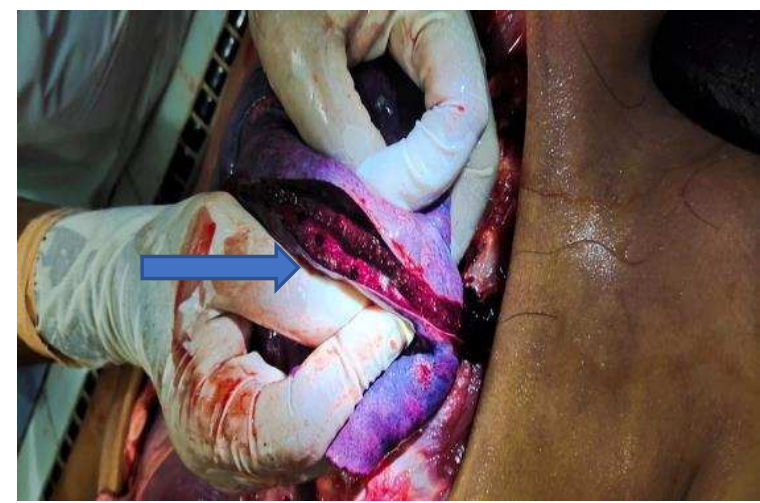

Figure 2. found a blackish-red diluted fluid mixed with fine foam that is difficult to break 

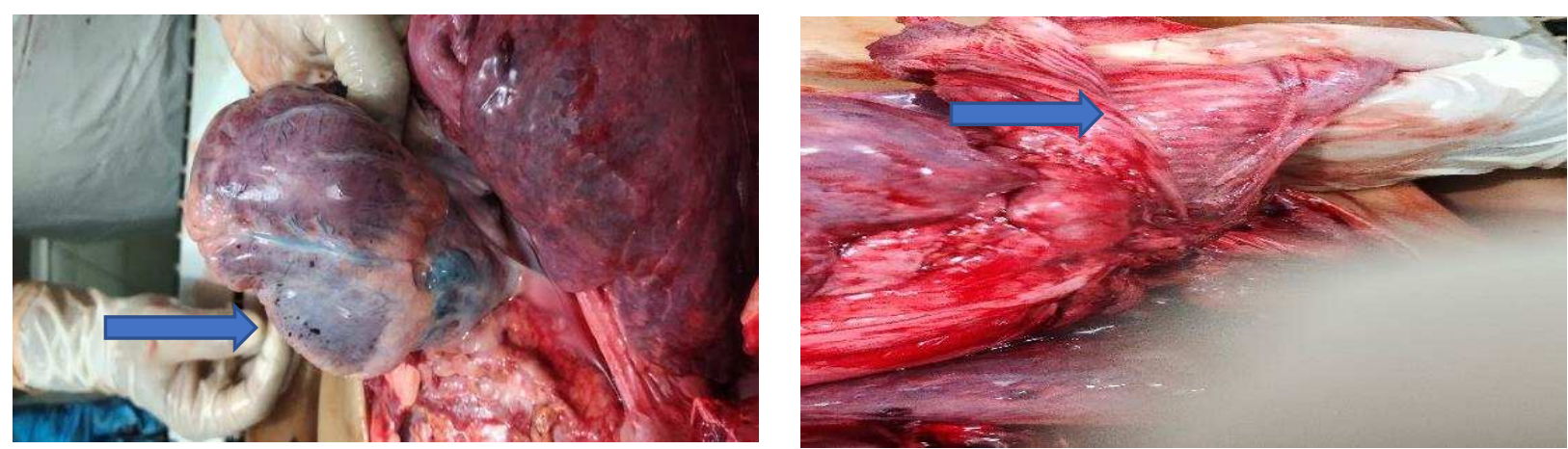

Figure 3. bleeding spots on the heart

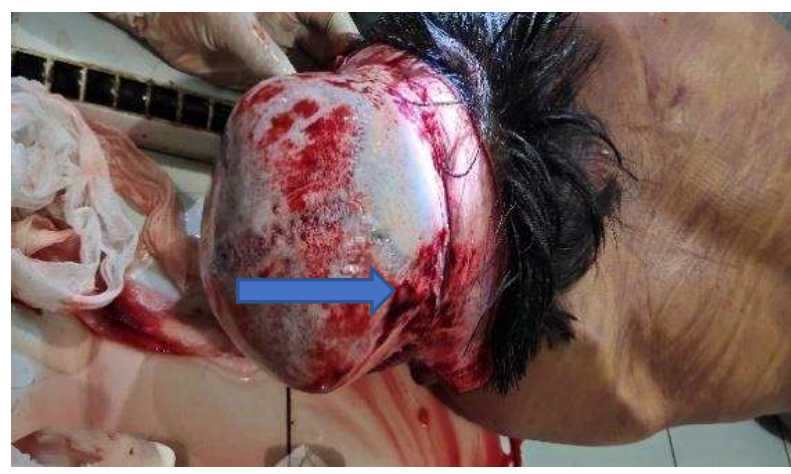

Figure 5. Blood catchment on the inside of the scalp

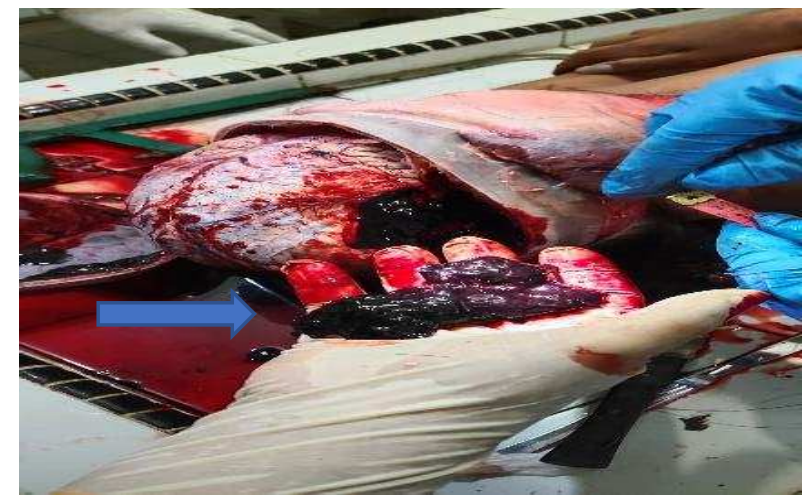

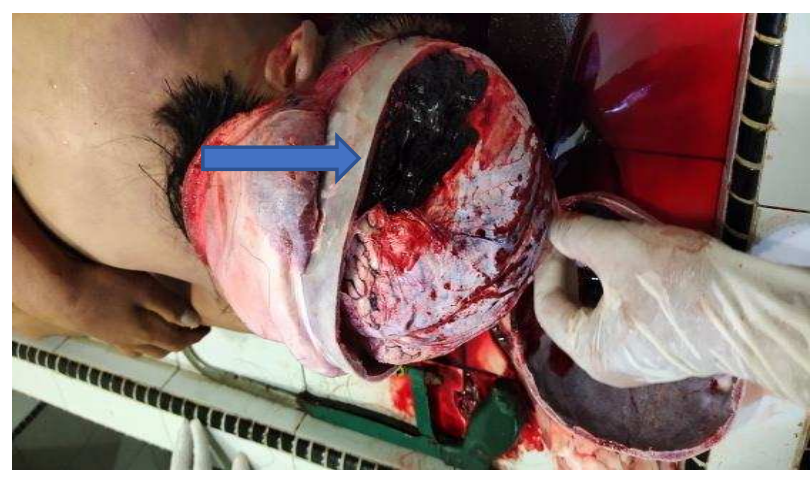

Figure 6. Blood clots above the thick membranes of the brain

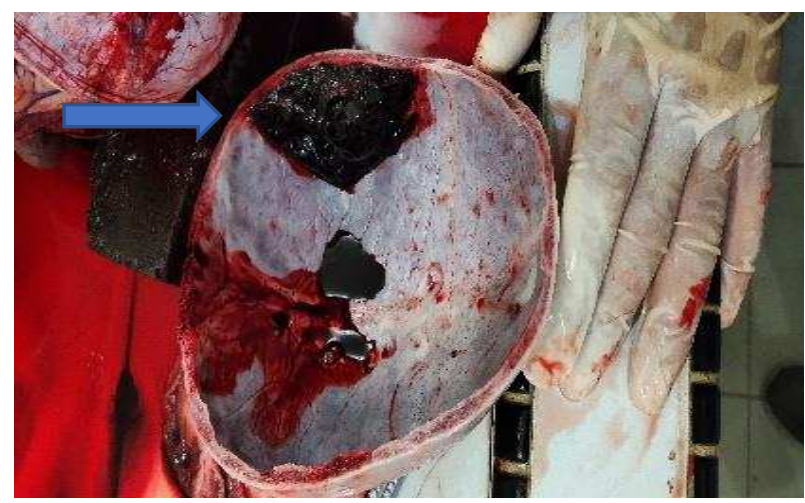

Figure 7 and 8 . blood clots on the surface of the thick membrane of the brain

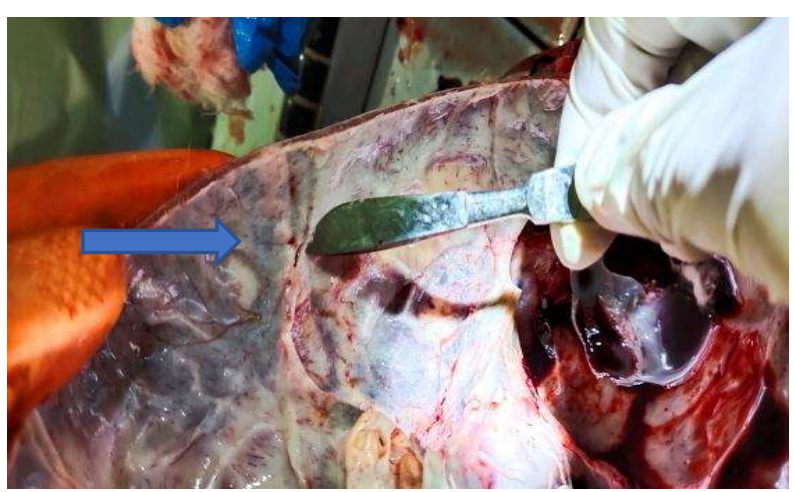

Figure 9. fractures of the base of the skull

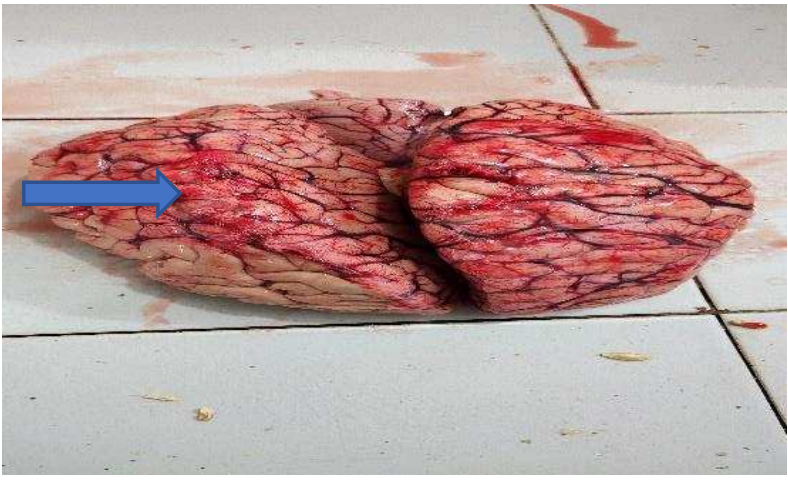

Figure 10. Brain 


\section{DISCUSSION}

- Found livor mortis on the neck, back, waist, upper and lower limbs that did not go away with pressure, found rigor mortis on the lower limbs that was easily resisted, found the lower right abdomen greenish and hair easily pulled out this indicates that the post mortem interval is 24 to 36 hours.

- External examination revealed bruises on the head and forehead. Based on the above theory, this suggests that the victim suffered blunt trauma to the head and forehead.

- Found bluish lips, the tips of the fingers are bluish, the tips of the toes are pale. Bleeding spots were found in the lungs and heart, on cutting the lungs found a red-black watery fluid mixed with fine foam. Based on the above theory, this shows that the victim has asphyxia, a condition in which the oxygen content $(\mathrm{O} 2)$ decreases and the carbon dioxide $(\mathrm{CO} 2)$ content increases simultaneously in the blood and body tissues caused by impaired exchange of oxygen in the alveoli of the lungs with carbon dioxide in the capillary blood. lungs.

- The internal examination found blood infiltration on the inner scalp, blood clots on the surface of the thick membranes of the brain, skull base fractures. Based on the examination, the victim experienced an epidural hematoma, namely bleeding which occurred between the skull and dura mater due to a tear in one of the branches of the middle meningeal artery. Because this bleeding was from an artery, blood comes out in spurts and pulses. A fracture of the skull base was found, indicating a bleeding relationship with a linear fracture that severed a larger artery, causing bleeding. An enlarged hematoma in the temporal region caused pressure on the temporal lobe of the brain downward and inside. This pressure caused the medial lobe to herniate under the tentorium rim. The pressure of the herniated uncus on the arterial circulation, that maintained the reticular formation in the medulla oblongata, caused loss of consciousness. As the hematoma enlarges, the entire brain was shifted causing a large intracranial pressure. and this bleeding is the result of trauma to the forehead which is a coup

\section{Conclusion}

- Based on the results of the external and autopsy, the post mortem interval is 24 to 36 hours. And the cause of death is epidural hemorrhage which was due to the skull fractures by blunt force trauma on the head.

\section{REFERENCES}

1. Allan H. Ropper, Robert H. Brown, Adam's and Victor Principles of Neurology, Eight Edition, Cambridge, 2011, 757 - 758

2. Mark M., Heinrich M., Neurology, Forth Edition, Mumenthaler, 2004, 50

3. Mc.Donald D., Epidural Hematoma, www.emedicine.com

4. Lewis P. Rowland, Merritt's Neurology, Eleventh Edition, 2005, 1 - 29

5. Michael J. A., Clinical Neurology, Sixth Edition, William and Wilkins, Lange, 2007, 1

6. Catherine H., Clinical Neuropathology, Text and Colour Atlas, 2010, 261 - 268 
7. Sotirios A. Tsementtzis, M.D., Ph.D, Differential diagnosis in Neurology and Neurosurgery, Thieme Stuttgart, New York, 2000, 220 - 221

8. Larry E. Davis, Fundamentals of Neurologic Disease, 2011

9. RAC Hughes, Neurological Emergency, Forth Edition, London, UK, 2010, 34-62

10. Basil F Matta MB, Textbook of Neuroanaesthasia and Critical Care, Cambridge UK, 2011, $285-295$

11. Weisberg L.A, Garcia C., Strub R., Essentials of Clinical Neurology, Chapter 12. Head Trauma $1-8$ www.psychneuro.tulane.edu/neulect/

13. Stacey L. Chamberlin, Brigham Narins, The Gale Encyclopedia of Neurological Disorders, Thomson Gale, 2005, $346-347$

14. Jeremy C. G. M.A.,Ph.D., The Lucid Interval Associated With Epidural Bleeding : Evolving Understanding, Volume 118, United Kingdom, April $2013,739-745$. 